\title{
A APLICAÇÃO DA METODOLOGIA SENAI NO ENSINO SUPERIOR
}

\section{ARTIGO ORIGINAL}

BUENO, Rodolfo Cesar de Souza Barcellos ${ }^{1}$

FONTES, Dalbert Santana ${ }^{2}$

SOUSA, Francisco Claudecir Porfírio de ${ }^{3}$

REICH, Michelle ${ }^{4}$

PICARDO, Marta Cristina ${ }^{5}$

GUIMARÃES, Rejane Patrícia Brito ${ }^{6}$

${ }^{1}$ Pós-graduação em Docência na Educação Profissional e Tecnológica; MBA em Logística e Operações Globais; MBA em Marketing Empresarial; Bacharel em Administração de Empresas.

${ }^{2}$ Engenheiro civil, Especialista em Engenharia de Segurança do Trabalho e em Docência na Educação Profissional e Tecnológica.

${ }^{3}$ Especialização em educação profissional; Tecnólogo em Marketing; Técnico em Segurança do Trabalho.

${ }^{4}$ MSc. em Ciências Ambientais e Florestais, Especialização em Docência na Educação Profissional e Tecnológica, bacharel e licenciatura em Ciências Biológicas. ${ }^{5}$ DSc. em Processos Químicos e Bioquímicos, MSc. em Engenharia Química, Especialização em Docência na Educação Profissional e Tecnológica, Especialização em Segurança Aplicada aos Projetos de E\&P de Petróleo e bacharel em engenharia química.

6 Especialização em Administração e Planejamento Educacional, MBA Desenvolvimento Avançado de Executivos com ênfase em Gestão de Pessoas e Graduação em Pedagogia. 
BUENO, Rodolfo Cesar de Souza Barcellos. Et al. A aplicação da metodologia SENAI no Ensino Superior. Revista Científica Multidisciplinar Núcleo do Conhecimento. Ano 05, Ed. 03, Vol. 03, pp. 155-167. Março de 2020. ISSN: 24480959, Link de

acesso: https://www.nucleodoconhecimento.com.br/educacao/aplicacao-da$\underline{\text { metodologia }}$

\section{RESUMO}

A evolução tecnológica exige profissionais com qualificação diferenciada, voltada para o desenvolvimento de competências. A Metodologia SENAI de Educação Profissional é estruturada especificamente com esse intuito, através dos perfis profissionais. $O$ presente estudo teve por finalidade analisar a aplicação da Metodologia SENAI de Educação Profissional nos cursos de ensino superior, a fim de identificar os benefícios e desafios que esse método, baseado no desenvolvimento de competências poderá proporcionar ao ser incrementado neste nível de ensino. Este trabalho foi baseado em pesquisa bibliográfica, onde foi feito uma revisão da literatura, com base em material já produzido, constituído principalmente de livros e artigos científicos sobre o assunto. Para alcançar os resultados desse estudo utilizou-se a metodologia de pesquisa exploratória. Um dos aspectos que deve ser considerado é que os cursos de bacharelado são normatizados por diretrizes e devem cumprir os requisitos legais estabelecidos pelo Ministério da Educação e Cultura (MEC). Os docentes e os discentes também devem se adequar a essa metodologia, onde o processo de aprendizagem exige que professores e alunos assumam um papel mais ativo, um maior compromisso compartilhado e, no caso particular dos alunos, maior responsabilidade por sua própria aprendizagem. A inserção da Metodologia SENAI de Educação Profissional no nível superior é promissora, trazendo o ensino por competência, diferenciando da metodologia aplicada atualmente baseada na exposição de conteúdo.

Palavras-Chave: Educação Profissional, metodologia SENAI, Ensino Superior. 


\section{INTRODUÇÃO}

Por um longo período predominava no contexto universitário que um docente bem qualificado deveria ter uma boa comunicação e amplo conhecimento específico na disciplina que iria atuar. Com a globalização, o avanço crescente das tecnologias e as novas formas de produção que demandam trabalhadores com uma qualificação diferenciada, voltada para o desenvolvimento de competências, exigindo uma formação do profissional de excelência.

A Metodologia SENAI de Educação Profissional é estruturada especificamente para essa finalidade através da criação dos Perfis Profissionais, oriundos de uma análise funcional, centrada nos resultados que o trabalhador deve apresentar. Mas será que as escolas de ensino superior têm essa mesma preocupação? E os cursos de bacharelado? São reflexões necessárias para que a educação corresponda às demandas reais da vida e do trabalho.

A proposta da pesquisa e do desenvolvimento no referido trabalho é evidenciar as necessidades de adequação da metodologia das instituições de ensino superior, estruturando-se a partir da metodologia SENAI de ensino. Apresentando os benefícios para capacitar profissionais de excelência, atendendo dessa forma as exigências do novo perfil que o mercado de trabalho exige e dentro desse contexto uma questão ganha força: como acomodar todos esses novos perfis profissionais na aprendizagem, sem estender estudos ou perder a profundidade no nível superior? Esse paradigma é o foco de análise da pesquisa.

Diante de mudanças nas características do processo de ensino aprendizagem, devido ao mundo tecnológico de hoje fornecer diversas fontes de conhecimento, há uma evolução no mundo que nos encaminha a um novo modo de ensinar. O mercado hoje exige um profissional com habilidades de comunicação, trabalho em equipe multidisciplinar, e habilidades de aprendizagem ao longo de sua carreira. Atualmente, os cursos de bacharelado ainda não possuem itinerário formativo conforme a Metodologia SENAI de Educação, tendo os cursos, o modelo ainda fragmentado em 
disciplinas, que compromete a interdisciplinaridade e o desenvolvimento do aprender a aprender e das capacidades sociais e organizativas.

O presente estudo objetiva analisar a aplicação da metodologia SENAI de Educação Profissional nos cursos de ensino superior, discutindo a metodologia atual de ensino e aprendizagem nas universidades do Brasil, apresentar a Metodologia SENAI e sua relação com o mundo do trabalho e verificar sua aplicabilidade da Metodologia SENAI nos cursos de bacharelado.

A fim de alcançar os objetivos desse estudo utilizou-se a metodologia de pesquisa exploratória, com o intuito de explicitar os desafios levantados e construir possíveis hipóteses e utilizou-se a pesquisa bibliográfica constituída principalmente de livros e artigos científicos. O presente trabalho possui como principais referências a Metodologia SENAI de Educação Profissional, a resolução que traz as instruções curriculares nacionais para os cursos de engenharia e o instrumento utilizado na avaliação de cursos de graduação presencial e a distância do MEC.

\section{DESENVOLVIMENTO}

\subsection{A METODOLOGIA ATUAL DO ENSINO SUPERIOR NAS UNIVERSIDADES BRASILEIRAS E SEUS DESAFIOS PARA ATENDIMENTO DO MERCADO DE TRABALHO}

O desenvolvimento do ensino superior ao longo da história da educação brasileira ocorreu morosamente. A realização de cursos superiores no período colonial correspondia à necessidade de formação de profissionais que servissem ao Rei e à Corte Portuguesa. A partir dos anos 20 , houve significativas mudanças na estrutura organizacional das universidades brasileiras. Não obstante, o sistema universitário do país passou por algumas reformas ao longo do século $X X$ a fim de se tornar um espaço mais democrático, de produção de saberes, de questionamentos, de formação de cidadãos e também na investida de minimizar a reprodução das desigualdades sociais. A universidade no Brasil desde a sua inserção era um espaço restrito à elite (LIMA, 2010). 
O modelo que o Brasil adotou tendo como base as escolas jesuítas, ou seja, escolas de fundo cristão, neste caso o cristianismo visava poder manter - se, disseminar sua doutrina e garantir o exercício do culto. A programação de estudos era composta pelo Trivium e Quadrivium, que segundo Durkheim, 1995, p.52 (apud PEINADO, 2018):

Tinha por objetivo ensinar a própria mente, isto é, as leis às quais obedece ao pensar e expressar seu pensamento, e, reciprocamente, as regras às quais deve sujeitar-se para pensar e expressar-se corretamente. Tal é, com efeito, a meta da gramática, da retórica e da dialética. Esse triplo ensino é, pois, totalmente formal. O Quadrivium[...] era um conjunto de conhecimentos relacionados com as coisas. Seu papel era tornar conhecidas as realidades externas e suas leis, leis dos números, leis do espaço, leis dos astros, leis dos sons. Assim, as artes que abraçava eram chamadas artes reales ou physica.

No início do século $X X$, setenta por cento da população brasileira era analfabeta. Nos anos 60 cursar a universidade era uma possibilidade real de mudança e evolução social. Contudo, a reforma universitária se fazia urgente. Estudantes, durante esse período, se mobilizaram com a intenção pressionar o governo brasileiro para a reestruturação das universidades (LIMA, 2010).

De acordo com Lima e Neto (2015) nos últimos vinte anos, observou-se no Brasil um notável processo de crescimento de seu ensino superior, fazendo com que a educação superior deixasse de ser privilégio para poucas pessoas. A democratização da incorporação a esse nível de ensino é muito significativa, haja vista, as expectativas de ascensão social que the são inerentes, tornando a faculdade uma desejo possível para segmentos cada vez maiores da população.

Todavia, apesar de todo crescimento e acesso ao ensino superior, um ponto a ser discutido, é a formação do corpo docente das universidades, pois a sua grande maioria possui um quadro de professores que é bacharel e, que em geral, são desprovidos de uma formação pedagógica para trabalhar como educadores nas universidades e nas faculdades (JUNGLES E BERHENS, 2015). Os docentes 
ensinam de acordo com o que sabem, pela direção que recebem, conforme experiências vivenciadas ou situações observadas (LIMA \&NETO, 2015).

Atualmente a metodologia aplicada nas universidades brasileiras é conteudista, ou seja, prevalece a figura do professor como transmissor e detentor do conhecimento, indiscutível a ser memorizado. O modelo da aula expositiva e dialogada, acompanhado de exercícios para ser resolvidos pelos alunos, a avaliação e, até mesmo o castigo e o controle rígido pré-estabelecido universalmente, onde o aluno deve ser passivo e obediente, memorizar o conteúdo para a avaliação traz uma estrutura engessada de funcionamento do processo de ensino-aprendizagem. Os docentes tradicionalistas têm em sua essência a aplicação de provas como o único meio de avaliar seu discente, ou seja, através de números, era mensurada a capacidade dos alunos. Ocorreram várias mudanças na forma de ensino através das oportunidades de inovar. Com a evolução das tecnologias e os desafios impostos pelas dinâmicas de mercado, os docentes começaram a enfrentar e desenvolver uma melhor metodologia para lecionar. Observam-se as transformações da sociedade e a necessidade de modificar os métodos tradicionais de ensinar, de aperfeiçoar constantemente as práticas e os saberes docentes (VAILLANT \& MARCELO, 2012).

Objetivando uma formação apropriada para lecionar na educação superior, os professores buscam realizar mestrados e doutorados em educação, no entanto essa medida tem sido insuficiente para propor uma pedagogia universitária que corresponda às demandas atuais da sociedade e da educação. Outra realidade a ser considerada, referindo-se especialmente ao professor universitário titulado, em particular como stricto sensu é que estes tendem a priorizar a pesquisa e não o ensino (JUNGLES \& BERHENS, 2015).

Neste cenário o maior desafio é a inserção da metodologia SENAI (por competências) nas universidades, pois esta exige o desenvolvimento da autonomia dos discentes. Esta autonomia, segundo Lück (2000, p.16):

Não se resume, à questão financeira, nem é mais significativa nessa dimensão, e sim na política. Isto é, no que se refere à capacidade de 
tomar decisões compartilhadas e comprometidas e usar o talento e a competência coletivamente organizada e articulada, para a resolução dos problemas e desafios educacionais, assumindo a responsabilidade pelos resultados dessas ações, apropriando-se de seu significado e de sua autoria. Portanto, a descentralização é um meio e não um fim, na construção da autonomia, assim como esta é, também, um meio para a formação democrática dos alunos.

Sendo assim, necessita-se urgentemente oferecer processos contínuos de qualificação de professores para lecionar eficazmente na educação superior. Pois além de conhecimentos específicos relacionados a sua formação, o professor deve dominar também os fundamentos pedagógicos do processo de ensino-aprendizagem, que devem estar alinhados aos saberes de sua experiência e de sua produção científica (JUNGLES \& BERHENS, 2015). Dessa forma, acredita-se que uma formação direcionada à prática pedagógica dos professores, torna-se, uma demanda essencial a ser transposta no ensino superior.

\subsection{A METODOLOGIA SENAI DE EDUCAÇÃO PROFISSIONAL E SUA RELAÇÃO COM O MUNDO DO TRABALHO}

O contexto de competências preconizado pela MSEP (Metodologia SENAI de Educação Profissional), segue uma rigorosa estrutura pedagógica, amparada em educadores renomados, na legislação, em órgãos internacionais, como a UNESCO e com forte cunho científico, assegurando a eficácia da sua proposta de educar para a vida e especialmente para o mundo do trabalho.

Identificar as competências que são necessárias no mundo do trabalho e traduzi-las pedagogicamente para o mundo da educação, formando profissionais que correspondam às atuais demandas da contemporaneidade, é essencialmente a missão da MSEP, plenamente desenhada para esse fim. A Figura 1, abaixo, ilustra esse ideal. 
Figura 1 - Fluxo para definição da oferta formativa

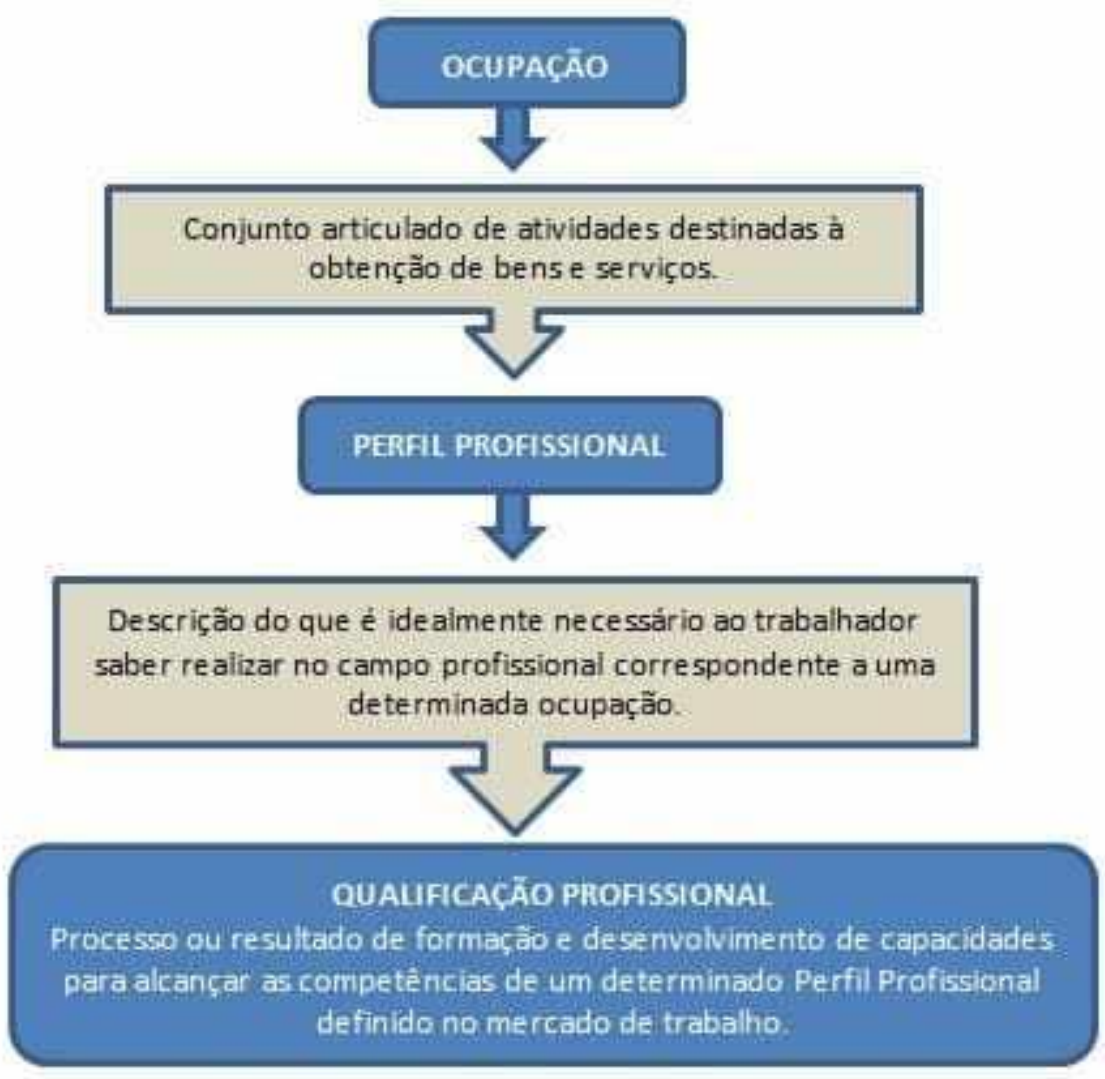

Fonte: SENAI, 2013. Adaptado pelo autor.

Em resumo, a ocupação representa o conjunto de competências reconhecidas no mercado de trabalho. O perfil profissional define o que é necessário ao trabalhador saber para atuar numa determinada ocupação e, a qualificação profissional, é o resultado de formação correspondente às competências necessárias de um perfil profissional.

Fica evidente que para o SENAI, competência está intimamente ligada a natureza do trabalho, na identificação dos conhecimentos, habilidades e atitudes requeridos ao profissional de certa ocupação, para a partir daí, educar e formar estudantes aptos (competentes) a ocuparem esses cargos, desempenhando com excelência suas atividades profissionais (SENAI, 2013). 
Para desenvolver eficazmente a qualificação profissional dos alunos, a MSEP propõe um desenho curricular com ofertas formativas correspondentes às diversas ocupações profissionais. Segundo SENAI (2013, p. 61):

O desenho curricular é o resultado do processo de concepção de ofertas formativas que devem propiciar o desenvolvimento das capacidades referentes às competências de um Perfil Profissional. Esse processo realiza a transposição das informações do mundo do trabalho para o mundo da educação, traduzindo pedagogicamente as competências de um Perfil Profissional.

Por meio do desenho curricular, o Perfil Profissional é desdobrado até chegar às capacidades técnicas e de gestão atinentes a uma profissão demandada pelo mercado de trabalho, assegurando um itinerário formativo compatível com o desenvolvimento de competências.

Nota-se uma sequência lógica na MSEP, pois, é traçado um Perfil profissional de acordo com o mercado de trabalho, elabora-se um desenho curricular com módulos, unidades curriculares e capacidades a serem desenvolvidas pelos discentes, e por fim, àquele que dará vazão a toda essa estrutura, o docente, que atuará em consonância com as práticas e princípios norteadores da Metodologia para desenvolver as competências dos seus alunos. E conforme SENAI (2013) esses princípios norteadores estão fundamentados nas teorias de Vygotsky, Piaget, Ausubel e Perrenoud.

Considerando a perspectiva do SENAI sobre competências, esse artigo, dentre outras coisas, objetiva identificar casos de aplicação de competências no ensino superior. Ressaltando de antemão, a impossibilidade de perceber a profundidade com que as instituições de Ensino Superior introduzem as competências em seus processos pedagógicos e a relação que as mesmas fazem com o mundo do trabalho. 


\subsection{VERIFICAÇÃO DA APLICABILIDADE DA METODOLOGIA SENAI AOS CURSOS DE BACHARELADO}

A metodologia SENAI apresenta características estimulantes e efetivas de aprendizagem, se tornando promissora a sua inserção no ensino superior. Porém, em qualquer processo de mudança encontramos algumas dificuldades, que costumam auxiliar na identificação de lacunas e pontos estratégicos, onde é possível o constante aprimoramento na aplicação desta metodologia.

Atualmente é notória a predominância de organizações curriculares ainda estruturadas em um nível multidisciplinar, onde os conhecimentos são parcelados em disciplinas isoladas, e os conteúdos não apresentam uma interligação (SENAI, 2014a). Porém, para a realidade do cotidiano de trabalho é fundamental a interação entre as disciplinas, com um currículo que seja baseado em unidades globais cronologicamente e estruturalmente organizadas, com conceitos e metodologias compartilhadas. Desta forma, a inserção da interdisciplinaridade na educação superior se mostra promissora para preparação do aluno para o trabalho, aprimoramento e adequação dos cursos na formação de profissionais capacitados. Entretanto a MSEP traz uma proposta de organização curricular que vai além da interdisciplinaridade, propondo a intensa cooperação entre os conteúdos, e a visão contextualizada dos conhecimentos. Assim têm-se as Unidades Curriculares, que contemplam um conjunto de capacidades técnicas e de gestão que o aluno deverá aprender para ser capaz de executar determinada função relacionada ao seu contexto profissional (SENAI, 2014a).

A organização curricular é de suma importância na educação de nível superior. Não só por organizar matérias/disciplinas em uma sequência lógica, na sua forma mais tradicional, mas também porque ela define o perfil do egresso, que deve ter não apenas competências técnicas, como também sociais. Os cursos de bacharelado possuem um desenho curricular baseado nas normas do Ministério da Educação e Cultura (MEC). As instituições de ensino não possuem autonomia para alterações, inserções e inovações nos cursos de bacharelado, necessitando de prévia aprovação 
do MEC para implementar tais ações. Por exemplo, a diretriz para as engenharias (Ministério da Educação, №: CNE/CES 1362/2001), prevê três núcleos no currículo: Básico, Profissionalizante e específico. De acordo com esta diretriz, o perfil do egresso é definido como:

Uma sólida formação técnico científica e profissional geral que o capacite a absorver e desenvolver novas tecnologias, estimulando a sua atuação crítica e criativa na identificação e resolução de problemas, considerando seus aspectos políticos, econômicos, sociais, ambientais e culturais, com visão ética e humanística, em atendimento às demandas da sociedade (Ministério da Educação, №: CNE/CES 1362/2001).

Competências como comunicar-se eficientemente, atuar em equipes multidisciplinares, ética e responsabilidade profissional, são previstas no desenho curricular dos cursos de engenharia. Estas competências estão sendo atualmente trabalhadas em disciplinas como Comunicação Oral e Escrita e Ética e Cidadania, de forma fragmentada. Porém, a Metodologia SENAI de Educação Profissional propõe que os conteúdos sejam trabalhados de forma interdisciplinar nas unidades curriculares incorporando as habilidades sociais, separando menos das competências técnicas e científicas. A matriz curricular para os cursos de graduação deve ser desenvolvida contemplando todos os conteúdos que as diretrizes determinam. Entretanto, a forma como os conteúdos serão trabalhados nesses cursos, devem permitir que o aluno desenvolva as capacidades técnica para que ele exerça as funções previstas no perfil profissional, demandado pela indústria.

As exigências do MEC e os requisitos legais que constam no instrumento de avaliação dos cursos de graduação devem ser atendidas de forma a constar no itinerário e nas situações de aprendizagem. Por exemplo, o instrumento de avaliação determina um número mínimo de bibliografia básica e complementar que deve estar presente no plano de curso. Desta forma, tanto o itinerário quanto as situações de aprendizagem devem conter esta bibliografia atendendo ao que é pré-estabelecido pelo Ministério da Educação (Instrumento de avaliação). 
A educação atual é pautada em torno de um bombardeamento de conhecimentos de diversas fontes, onde o papel do professor passa a ser de guia, direcionando e moldando este conhecimento. Na maioria das universidades no Brasil têm-se atualmente aulas clássicas, pouco interativas entre professores e alunos. As aulas expositivas podem ser úteis para o desenvolvimento de conhecimentos técnicos complexos. Entretanto, a atuação do professor está mudando de um transmissor de conhecimento para um mediador, que deverá apoiar o desenvolvimento da aprendizagem dos alunos. É importante ser sensível as mudanças no modo de ensino e aprendizagem. (HEINENDIRK \& ČADEŽ, 2013)

A indústria vem ao longo dos anos apontando algumas deficiências no ensino superior: excessivo conteúdo teórico com poucas atividades práticas, preparação insuficiente para liderar equipes de trabalho e pouco incentivo a criação e inovação. As Instituições de Ensino Superior têm como desafio adaptar-se as mudanças na sociedade de hoje e suas demandas. Diante do exposto, o modelo educacional concebido em um formato de competências profissionais atende as necessidades da indústria, que necessitam mais de profissionais competentes do que especialistas experientes (RíOS et al., 2010).

O Desenho curricular desenvolvido no modelo por competências requer maior planejamento docente. Há necessidade de interação entre todos os professores, que devem focar no desenvolvimento das capacidades técnicas, sociais, metodológicas e organizacionais no aluno, e não na sua disciplina unicamente. Esta é uma metodologia que retira o docente da sua individualidade no preparo das aulas e o torna mais participativo no planejamento integrado, visando o desenvolvimento de competências, utilizando ferramentas como os projetos que integram vários conhecimentos. Rios et al. (2010) descreve o esforço para conscientizar os professores da necessidade de mudança e adaptação as novas demandas do mundo profissional, principalmente relacionado ao planejamento dos conteúdos didáticos que devem ter sempre como referência as competências profissionais.

Discentes e docentes podem precisar de algum tempo para se adaptar com novos formatos de aulas, papéis e responsabilidades em seus ensinamentos e aprendizado. 
Os conhecimentos não são expostos como nos currículos tradicionais. Essas informações devem sempre responder a seguinte pergunta: "O que o aluno precisa saber para desenvolver determinada capacidade?" Portanto, os professores precisam avaliar quais conteúdos realmente contribuem para o desenvolvimento das capacidades. (SENAI, 2014b)

$\mathrm{Na}$ educação baseada em competências, o aluno tem que saber fazer, aprender a conhecer e aprender a agir (SENAI, 2014c), alcançando resultados duradouros. Esta visão pode deixar transparecer em alguns momentos que o ciclo básico, das engenharias por exemplo, perderia a sua função ou necessidade, mas na verdade ganham muito mais importância, com a aplicação e interdisciplinaridade nas áreas específicas. Bem como aqueles conteúdos que perpassam por todo o currículo, como os aspectos relacionados ao meio ambiente, por exemplo, podem ser abordados de forma interdisciplinar em várias unidades curriculares através de projetos integradores e voltados para o impacto ambiental e social, visando melhoria da vida de uma determinada comunidade.

De acordo com o Espaço Europeu de Ensino superior (apud RíOS et al., 2010), as medidas necessárias para alcançar a empregabilidade é a aprendizagem de competências transversais, como a comunicação, capacidade de lidar com informações, resolver problemas, trabalhar em equipes e liderar processos sociais. Os discentes saem de uma posição de espectadores e passam a ser atores participantes do seu processo de aprendizagem. Estes, não só absorvem o conteúdo transmitido pelo professor, mas passam a trazer informações e construir os seus conhecimentos em conjunto com os outros atores. Em modelos educacionais que integram a aprendizagem através de projetos têm sua base científica na geração de processos de aprendizagem em que os alunos não são recipientes passivos de conhecimento (CHINNOWSKY et al., 2006). Diante do exposto, o aluno passa ter o compromisso de aprender a aprender, desenvolvendo suas capacidades através das situações de aprendizagem, que trazem uma simulação de realidades vivenciadas no cotidiano de trabalho, preparando-os para o mercado. Porém em qualquer mudança existe a necessidade de adaptação. Para compreensão dos discentes dessa nova 
metodologia de aprendizado, se torna imprescindível o entendimento por parte dos mesmos, dos ganhos da preparação para sua atuação profissional através do método baseado no desenvolvimento de capacidades, que busca através da estrutura cronológica das unidades curriculares, abordar os conhecimentos cabíveis ao seu perfil profissional.

Desta maneira, muitos são os desafios trazidos para implantação da metodologia SENAI no nível superior de ensino, onde adequações são necessárias para que a mesma atenda aos requisitos estipulados pelo MEC. Porém vale ressaltar que para o sucesso desta metodologia, os docentes devem se adequar a maneira de ensinar e os discentes devem conhecer a metodologia, a fim de aceitá-la e, absorver da melhor maneira, os conhecimentos a partir do desenvolvimento de capacidades.

\section{CONCLUSÃO}

Diante do exposto no presente trabalho, a metodologia de ensino atualmente empregada nas universidades brasileiras é baseada, em sua maioria, em aulas expositivas e dialogadas, onde o professor é visto como detentor do conhecimento e o aluno deve reproduzi-lo. Esta metodologia prevê uma maneira diferenciada do desenvolvimento de capacidades no discente, estando o conteúdo desconectado das competências que o aluno deve ter para o mercado de trabalho.

A metodologia para o desenvolvimento de competências vincula o ensino com a realidade profissional, é baseada em cooperação, participação ativa e interação, oferecendo múltiplas possibilidades de desenvolvimento. $O$ processo de aprendizagem exige que professores e alunos assumam um papel mais ativo, um maior compromisso compartilhado e, no caso particular dos alunos, maior responsabilidade por sua própria aprendizagem.

Na Metodologia Senai é necessária a conscientização dos docentes sobre as novas exigências do mercado de trabalho, onde diferentes competências devem ser trabalhadas a fim de formar um profissional mais completo. $O$ desenho curricular baseado em competências requer um planejamento que permita uma interação mais 
intensa entre os professores. Os docentes devem concentrar-se em desenvolver nos seus alunos as capacidades técnicas, sociais, metodológicas e organizativas, e não na sua disciplina unicamente. Esta é uma metodologia que retira o docente da sua individualidade no preparo das aulas e o torna mais participativo no planejamento integrado, visando o desenvolvimento de competências, utilizando ferramentas como os projetos que integram vários conhecimentos.

Para atingir os objetivos da implantação de uma metodologia baseada em competências nos cursos de bacharelado, se torna imprescindível a mudança de postura do professor em sala de aula, passando de detentor do saber para mediador da construção do conhecimento. Já os discentes devem se adaptar a esta nova estrutura de ensino, onde ele é motivado a "aprender a aprender".

Desta forma, não existem maiores impeditivo para a inserção da Metodologia SENAI de Educação Profissional no nível superior, porém são necessárias adaptações a fim de melhor adequá-la à realidade das graduações, pois os cursos de bacharelado são controlados por normas, devendo cumprir os requisitos legais estabelecidos pelo MEC. Além disso, são necessários esforços a fim de conscientizar alunos e professores da integração do conhecimento e atuação participativa no processo de ensino aprendizado, com o objetivo de formar um profissional competente que corresponda as atuais exigências do mercado.

\section{REFERÊNCIAS}

CHINNOWSKY, P., BROWN, H., SZAJNMAN, A., REALPH, A. Developing knowledge landscapes through project-based learning. Journal of Professional Issues in Engineering Education and Practice, 132, (2), 2006.

HEINENDIRK, E.M.,ČADEŽ, I. Innovative Teaching In Civil Engineering With Interdisciplinary. Team Work, Organization, Technology and Management In Construction an International Journal, 5, (2), 2013. 
JUNGLES, Kelen; BEHRENS, Marilda. Prática docente no Ensino Superior: a formação pedagógica como mobilizadora de mudança.2015.Disponível em:<https://periodicos.ufsc.br/index.php/perspectiva/article/view/2175795X.2014v33 n1p285/31220 > .Acesso em: 20 nov. 2017.

LIMA, Keite. Metodologia do ensino superior. Módulo XI.2010.Disponível em:<https://www.institutoprosaber.com.br/avapos/material/comum/n/11_metodologia _ensino_superior.pdf> Acesso em: 20 nov. 2017.

LIMA, Silene; NETO, Francisco. Desafios na prática pedagógica do docente iniciante em instituições de ensino superior.2015.Disponível em: http://fameta.edu.br/media/files/35/35_1200.pdf $\geq$ Acesso em: 20 nov. 2017.

LÜCK, Heloísa. Gestão escolar e formação de gestores. Periódico em aberto, Brasília, DF, fev.jun. 2000.

MINISTÉRIO DA EDUCAÇÃO, parecer №: CNE/CES 1362/2001. Disponível em: http://portal.mec.gov.br/cne/arquivos/pdf/CES1362.pdf, Acesso em: 24 nov. 2017.

PEINADO, Maria Rita Sefrian de Souza. O Ponto Dentro do Círculo. Disponível em:< https://opontodentrodocirculo.wordpress.com/2016/12/20/santo-agostinho-trivium-equadrivium-parte-i/> Acesso em: 06 fev. 2018.

RÍOS, I., CAZORLA, A., DÍAZ-PUENTE, J.M., YAGUE, J.L. Project-based learning inengineering higher education: two decades of teaching competences in realenvironments. Procedia Social and Behavioral Sciences, 2, 2010.

SENAI. Departamento Nacional. Metodologia SENAI de educação profissional. / SENAI. Departamento Nacional. - Brasília: SENAI/DN, 2013.

SENAI. Departamento Nacional. Metodologia SENAI de educação profissional. / SENAI. Departamento Nacional. - Brasília: SENAI/DN, 2013. 
. Organização Curricular da educação profissional e tecnológica. PósGraduação em Docência na Educação Profissional e Tecnológica. SENAI CETIQT, 2014. (a)

Educação Profissional: A prática da metodologia Senai. Pós-Graduação em Docência na Educação Profissional e Tecnológica. SENAI CETIQT, 2014. (b)

. Planejamento do Processo de Ensino Aprendizagem. Pós-Graduação em Docência na Educação Profissional e Tecnológica. SENAI CETIQT, 2014. (c)

VAILLANT, D. MARCELO, C. Ensinando a ensinar: as quatro etapas de uma aprendizagem. Curitiba: UTFPR, 2012. Acesso em: 27 nov. 2017.

Enviado: Agosto, 2019.

Aprovado: Março, 2020. 